\title{
MECHANORECEPTORS IN THE PALMAR WRIST LIGAMENTS
}

\author{
S. PETRIE, J. COLLINS, M. SOLOMONOW, C. WINK, R. CHUINARD \\ From Louisiana State University Medical Center, New Orleans, USA
}

Three palmar wrist ligaments from fresh human cadavers were dissected from the proximal to the distal insertions and stained to identify the mechanoreceptors. Golgi organs, Pacinian corpuscles, Ruffini endings and free nerve endings were present in all three ligaments. In the radial collateral and radiolunate ligaments they were found in increased density towards the proximal and distal insertions. A more uniform distribution was found in the radioscaphocapitate ligament which has attachments to three bones.

The palmar wrist ligaments may have a significant sensory role in maintaining the stability of the wrist and in controlling its movement. Although technically difficult, the surgical repair of traumatic wrist defects should attempt to preserve the innervation of the ligaments, shown to be mainly near bony attachments. This may allow improvement in postoperative outcomes by preserving some proprioception. In some painful post-traumatic or degenerative conditions, however, denervation may be advantageous.

J Bone Joint Surg [Br] 1997;79-B:494-6.

Received 25 November 1996 ; Accepted after revision 4 February 1997

The sensory role of ligamentous mechanoreceptors, found in several joints, ${ }^{1-3}$ is important for preserving the mechanical stability of the joint ${ }^{4,5}$ via a reflex arc, ${ }^{6-9}$ for preventing degenerative joint disease ${ }^{10}$ and for allowing the optimal control of movement. ${ }^{11}$
S. Petrie, MD, Research Resident

J. Collins, MD, Research Resident

M. Solomonow, PhD, Professor, Director of Bioengineering

R. Chuinard, MD, Professor, Vice-Chairman

Bioengineering Laboratory, Department of Orthopaedic Surgery

C. Wink, PhD, Associate Professor

Department of Anatomy

Louisiana State University Medical Center, New Orleans, Louisiana 70112, USA.

Correspondence should be sent to Professor M. Solomonow at the Department of Orthopaedic Surgery, 2025 Gravier Street, Suite 400, New Orleans, Louisiana 70112, USA

(C)1997 British Editorial Society of Bone and Joint Surgery 0301-620X/97/37439\$2.00
There are no reports of the detailed innervation of the wrist ligaments or whether there are mechanoreceptors in these ligaments. Our aim was to determine whether mechanoreceptors were present in the palmar wrist ligaments.

\section{MATERIALS AND METHODS}

We used six cadaver wrists within 24 hours of death. The radial collateral (RC), radioscaphocapitate (RSC) and radiolunate (RL) ligaments (Fig. 1) were removed as close as possible to their bony insertions. The radial side of each ligament was marked.

The ligaments were immediately placed in saline and processed by staining in bulk using a modified gold-chloride method. ${ }^{12}$ The stained ligaments were frozen before sections $100 \mu \mathrm{m}$ thick were cut perpendicular to the

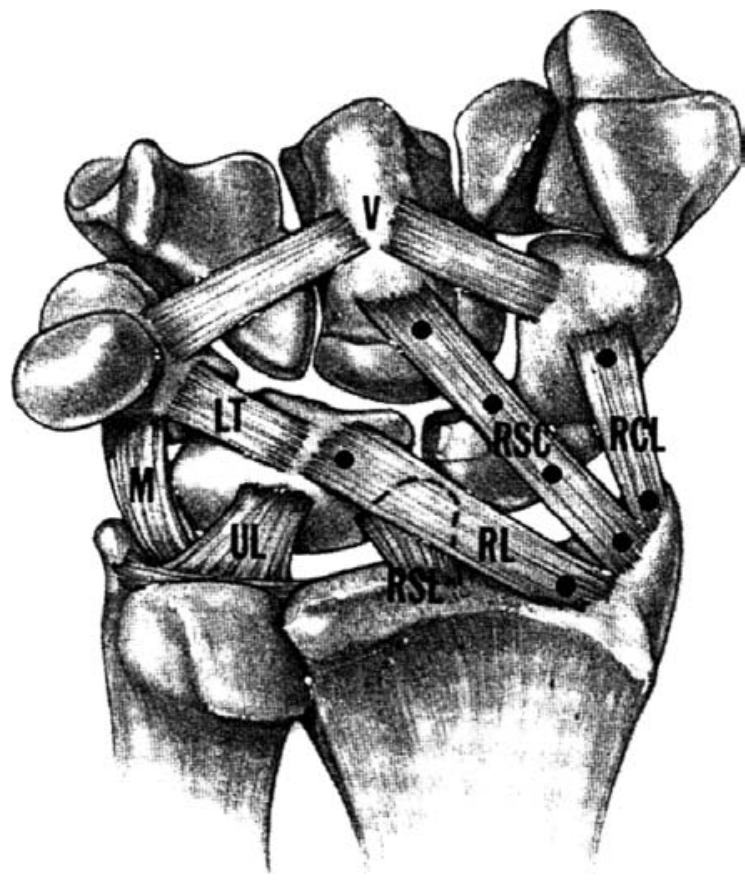

Fig. 1

Diagram showing the radial collateral (RCL), the radiolunate (RL) and the radioscaphocapitate (RSC) ligaments. The location of the highest density of receptors in each ligament is indicated by solid circles (modified from Taleisnik ${ }^{13}$ ). 


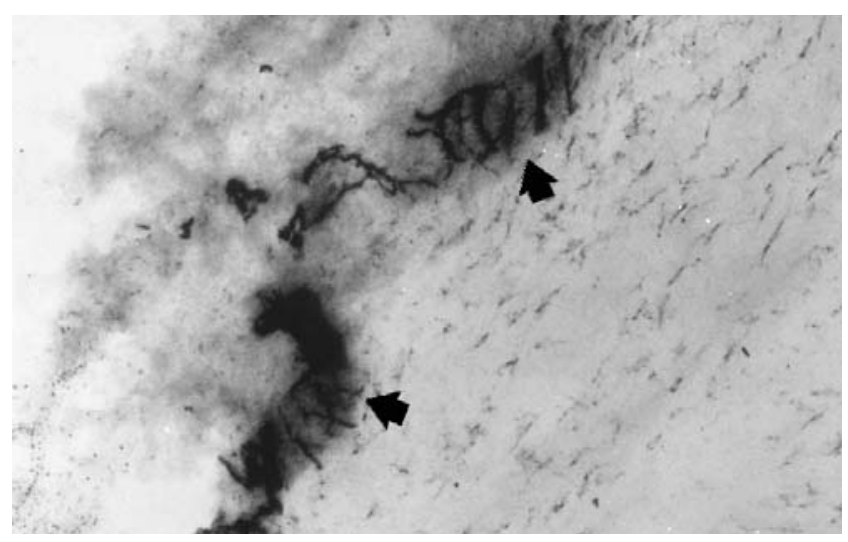

Fig. 2a

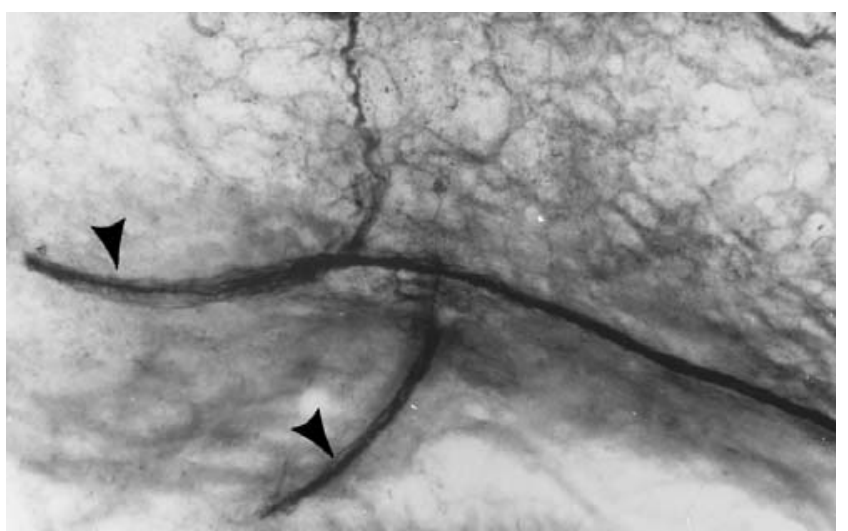

Fig. 2c

longitudinal axis of the ligament. All the sections were studied by light microscopy for the presence of mechanoreceptors. Emphasis was placed on identifying the types of mechanoreceptor as well as their distribution. The number of sections containing receptors was calculated as a percentage of all the sections from each ligament. Since the ligaments are intracapsular the sections were mostly taken from the length of the ligament excluding the area of the synovial membrane.

\section{RESULTS}

We identified four types of mechanoreceptor in the three ligaments; Golgi organs, Pacinian corpuscles, Ruffini endings and free nerve endings. Figure 2 illustrates typical examples taken from one specimen. Table I shows the number of sections made from each specimen and the number of sections that contained receptors. In the RC ligament mechanoreceptors were identified in $41 \%$ (368/903) of the sections, in the RL ligament in $29 \%$ $(447 / 1521)$ and in the RSC ligament in $22 \%$ (266/1221).

In the RC and the RL ligaments the density of the mechanoreceptors was greatest at their proximal and distal insertions whereas in the RSC ligament the mechanoreceptors were evenly distributed throughout the tissue.

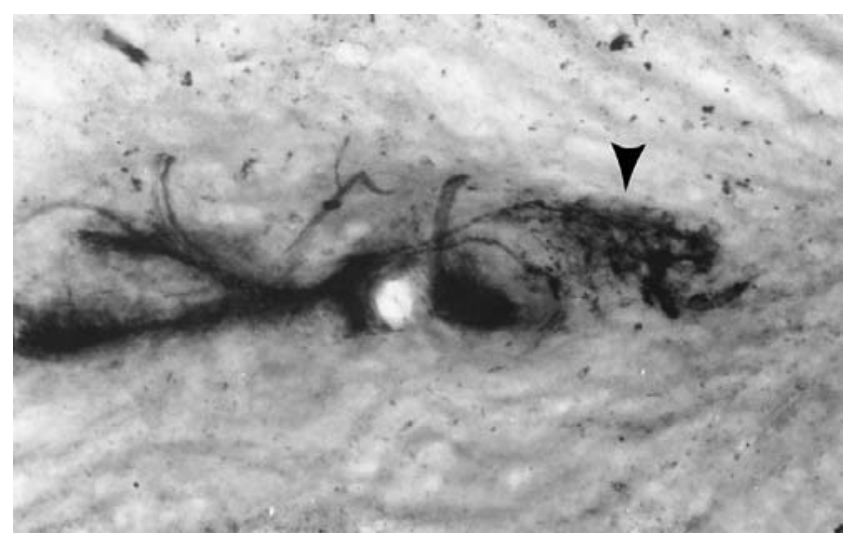

Fig. 2b

Photomicrographs showing the mechanoreceptors of the Golgi (a), Ruffini (b) and Pacinian (c) types in the RL (a) and RC ligaments (b and c), respectively $(\times 140)$.
Table I. The number of sections made from each specimen and the number and percentage of sections containing receptors

\begin{tabular}{|c|c|c|c|}
\hline & $\begin{array}{l}\text { Sections with } \\
\text { receptors }\end{array}$ & $\begin{array}{l}\text { Total } \\
\text { sections }\end{array}$ & $\begin{array}{l}\% \text { with } \\
\text { nerves }\end{array}$ \\
\hline \multicolumn{4}{|l|}{ RCL } \\
\hline 1 & 108 & 167 & 65 \\
\hline 2 & 43 & 152 & 28 \\
\hline 3 & 84 & 151 & 56 \\
\hline 4 & 12 & 90 & 13 \\
\hline 5 & 87 & 235 & 37 \\
\hline 6 & 34 & 108 & 31 \\
\hline Total & 368 & 903 & 41 \\
\hline \multicolumn{4}{|l|}{ RL } \\
\hline 1 & 55 & 145 & 38 \\
\hline $2 \mathrm{R}$ & 17 & 140 & 12 \\
\hline $2 \mathrm{~L}$ & 95 & 226 & 42 \\
\hline 3 & 42 & 147 & 29 \\
\hline $4 \mathrm{R}$ & 5 & 126 & 4 \\
\hline $4 \mathrm{~L}$ & 65 & 318 & 20 \\
\hline 5 & 78 & 161 & 48 \\
\hline 6 & 90 & 258 & 35 \\
\hline Total & 447 & 1521 & 29 \\
\hline \multicolumn{4}{|l|}{ RSC } \\
\hline 1 & 48 & 275 & 17 \\
\hline 2 & 18 & 206 & 9 \\
\hline 3 & 37 & 170 & 22 \\
\hline 4 & 80 & 235 & 34 \\
\hline 5 & 8 & 154 & 5 \\
\hline 6 & 75 & 181 & 41 \\
\hline Total & 266 & 1221 & 22 \\
\hline
\end{tabular}


Figure 1 also shows the location in each ligament at which the highest density of mechanoreceptors was found.

\section{DISCUSSION}

Our results confirm the presence of mechanoreceptors in the palmar ligaments of the wrist. They consisted of Golgi organs, Pacinian corpuscles, Ruffini endings and free nerve endings which can signal transient as well as continuous events due to their combined fast- and slow-adapting characteristics. The free nerve endings can also relay pain sensation due to excessive deformation or damage to the tissue.

The increased density of mechanoreceptors in the proximal and distal ends of the RC and RL ligaments implies a specific function. The mid-substance of the ligaments is relatively more compliant compared with their insertion into the respective bones. The mechanoreceptors, being sensitive to the extent of the deformation of the tissue in which they are embedded, are therefore less responsive to strain when near the stiffer proximal and distal insertions. They may signal relatively large strains which could subject the ligament to excessive deformation and possible damage.

Review of the structure of the RSC ligament shows that it originates from the triangular surface of the anterior aspect of the radial styloid and inserts distally on the capitate. It crosses the scaphoid on to which it also gains an attachment; ${ }^{13}$ this probably gives rise to the increased population of receptors shown by the black circles in Figure 1. There is thus a more even distribution of mechanoreceptors in this ligament, but the functional implications of the distribution are probably similar to those of the RC and RL ligaments.

Our findings confirm the presence of mechanoreceptors in the palmar wrist ligaments, suggesting that there is a ligamentomuscular protective reflex in the wrist. They also indicate that, although technically difficult, surgical repairs of the wrist should attempt to preserve the articular nerves of the ligaments. Nevertheless, in some painful post-traumatic or degenerative conditions, it may sometimes be desirable to denervate the joint.

This work was supported by the National Science Foundation with Grant BCS 9207007. Drs Petrie and Collins were research residents supported by the Department of Orthopaedics.

No benefits in any form have been received or will be received from a commercial party related directly or indirectly to the subject of this article.

\section{REFERENCES}

1. Zimny M, Wink C. Neuroreceptors in the tissues of the knee. J Electromyogr Kinesiol 1991;1:148-57.

2. Freeman MA, Wyke B. The innervation of the ankle joint: an anatomical and histological study in the cat. Acta Anat Basel 1967; 68:321-33.

3. Solomonow M, Guanche C, Wink C, et al. Mechanoreceptors and reflex arc in the feline shoulder. J Shoulder Elbow Surg 1996;5: 139-46.

4. Hirokawa S, Solomonow M, Luo Z, Lu Y, D'Ambrosia R. Muscular co-contraction and control of knee stability. J Electromyogr Kinesiol 1991;1:199-208.

5. Pope M, Stankewich C, Beynnon B, Fleming B. Effect of knee musculature on anterior cruciate ligament strain in vivo. $J$ Electromyogr Kinesiol 1991;1:191-8.

6. Ekholm J, Eklund G, Skoglund S. On the reflex effects from the knee joint of the cat. Acta Physiol Scand 1960;50:167-74.

7. Guanche C, Knatt T, Solomonow M, et al. The synergistic action of the capsule and the shoulder muscles. Am J Sports Med 1995;23: 301-6.

8. Lewis J, Donatto K, Solomonow M. Ligamento-muscular protective reflex in the feline ankle. Orthop Int 1996;4:359-65.

9. Solomonow M, Baratta R, Zhou BH, et al. The synergistic action of the anterior cruciate ligament and thigh muscles in maintaining joint stability. Am J Sports Med 1987:207-13.

10. O'Conner BL, Visco DM, Brandt KD, Myers SL, Kalansinski LA. Neurogenic acceleration of osteoarthrosis: the effects of previous neurectomy of the articular nerves on the development of osteoarthrosis after transection of the anterior cruciate-ligament in dogs. $J$ Bone Joint Surg [Am] 1992;74-A:367-76.

11. Johansson H. Role of knee ligaments in proprioception and regulation of muscle stiffness. J Electromyogr Kinesiol 1991;1:158-79.

12. Gairns F. Modified gold chloride method for the demonstration of nerve endings. QJ Microsc Sci 1930;74:151-5.

13. Taleisnik J. The wrist. New York, Churchill Livingstone, 1985. 